\title{
Microvessels in Epithelial Ovarian Tumors: High Microvessel Density Is a Significant Feature of Malignant Ovarian Tumors
}

\author{
MINNA SOPO $^{1}$, MAARIT ANTTILA ${ }^{1,2}$, OONA-TUULI MUUKKONEN ${ }^{3}$, SEPPO YLÄ-HERTTUALA $^{4,5}$, \\ VELI-MATTI KOSMA ${ }^{6,7,8}$, LEEA KESKI-NISULA ${ }^{1,2}$ and HANNA SALLINEN ${ }^{1,2,4}$ \\ ${ }^{1}$ Department of Gynecology, Kuopio University Hospital, Kuopio, Finland; \\ ${ }^{2}$ Institute of Clinical Medicine, School of Medicine, Gynaecology, ${ }^{7}$ Pathology and Forensic Medicine, and \\ ${ }^{8}$ Cancer Center of Eastern Finland, University of Eastern Finland, Kuopio, Finland; \\ ${ }^{3}$ Department of Health Sciences, Clinical Medicine, University of Eastern Finland, Kuopio, Finland; \\ ${ }^{4}$ Department of Biotechnology and Molecular Medicine, A.I.Virtanen Institute for Molecular Sciences, \\ University of Eastern Finland, Kuopio, Finland; \\ ${ }^{5}$ Gene Therapy Unit, Kuopio University Hospital, Kuopio, Finland; \\ ${ }^{6}$ Department of Pathology and Forensic Medicine, Kuopio University Hospital, Kuopio, Finland
}

\begin{abstract}
Background/Aim: Examine features of blood and lymphatic vessels in ovarian tumors and their significance to prognosis of ovarian cancer. Patients and Methods: A total of 139 women with epithelial ovarian tumors were included: 86 malignant, 17 borderline and 36 benign. Density, percentage, mean size and number of blood microvessels in tumors were measured by immunohistochemistry with antibodies against CD34 and CD105. Lymphatic vessel density was assayed using the D2-40 antibody against podoplanin. Results: Angiogenesis was most profuse in malignant tumors. Small size of lymph vessels predicted $26 \%$ shorter 5-year survival of ovarian cancer patients. Further, high percentage of lymphatic vessels in tumors was associated with lymph node metastasis, and high density with cancer recurrence. Lower number of microvessels, as assessed by CD34 staining, predicted shorter progression-free survival. Additionally, the large size of microvessels assessed by CD34 and the high number of vessels assessed by CD105 were related to residual tumor $>1$ $\mathrm{cm}$ at primary surgery and also, large vessel size was associated with stage III, as assessed by CD105 staining. Conclusion: CD34 and CD105 define different characteristics of microvessels. Parameters of lymph vessels may predict the prognosis of ovarian cancer.
\end{abstract}

This article is freely accessible online.

Correspondence to: Minna Sopo, Department of Gynecology and Obstetrics, Kuopio University Hospital, P.O. Box 100, FIN-70029 Kuopio, Finland. Tel: +358 447175170, e-mail: minna.sopo@kuh.fi

Key Words: Ovarian cancer, immunohistochemistry, angiogenesis, lymphangiogenesis, CD105, CD34.
Ovarian cancer has the worst prognosis among all gynecological malignancies. Due to its treacherous nature, it is often diagnosed in advanced stage (70\%). In spite of the primary treatment: cytoreductive ultraradical surgery and chemotherapy with carboplatin and paclitaxel, disseminated or recurrent ovarian cancer can rarely be completely cured, the 5-year survival still being $27 \%(1,2)$.

Targeted treatment strategies have ushered in a new era in cancer therapy. The antiangiogenic monoclonal vascular endothelial growth factor (VEGF) antibody bevacizumab, has been part of the standard care of stage IV and III suboptimally debulked primary cancer, as well as of recurrent ovarian cancer $(3,4)$. In addition, an antiangiogenic approach has been combined poly (ADP-ribose) polymerase (PARP) inhibition and immunological checkpoint inhibitors in ongoing trials to boost the treatment effect $(5,6)$. However, optimal method for selecting patients for the antiangiogenic therapy is still obscure; it includes biomarkers and the knowledge of the diagnostic characteristics of the disease, prognostic means and follow up of treatment efficacy.

Due to neoangiogenesis, the structure of the vessels in malignant tumors differs from that of the normal ones. In malignant tumors, microvessels are curvier and organized more irregularly (7). Further, their walls are more fragile since the endothelial cells are weakly connected to each other and to the pericyte layer (8), and the basal membrane has also only loose contact with the pericytes (9).

Hypoxia activates angiogenesis in tumors. VEGF has an important role in the growth of endothelial cells. VEGF-C and $-\mathrm{D}$, activate vascular endothelial growth factor receptor 3 (VEGFR3), and are in turn vital for the development of lymph vessels (10). In several studies, VEGF has been shown to be over-expressed in many malignancies like 
breast, ovary, endometrium and bladder tumors (11); however, controversial results have also been described (12).

Microvessel density describes the intensity of angiogenesis in the tumors. Several studies have shown that high microvessel density, VEGF levels and the expression of VEGF receptors are associated with poor prognosis (13). On the other hand, there are contradictory results regarding the value of high microvessel density and its relation to prognosis. In some studies, it has been associated with a better prognosis $(14,15)$. It has been suggested that increased blood supply to the tumors enhances the access of the cytoreductive agents and oxygen to the tumor. There are also studies where a correlation between microvessel density and prognosis was not found (16).

Antibodies against cluster of differentiation 31 (CD31) and CD34 are used in immunohistochemical expression studies of the endothelium. Glycoprotein CD34 is expressed on the endoepithelial surface and on the cell membranes, connecting the layers of endothelial cells, and is also expressed in immature blood cells (17).

Endoglin, also known as CD105, is a cell membrane homodimeric glycoprotein and a part of the transforming growth factor (TGF- $\beta$ ) receptor complex. Endoglin is expressed by rapidly dividing endothelial cells and is vital for angiogenesis. Endoglin has been related to newly formed blood vessels, while CD34 is expressed in both old and newly formed vessels $(17,18)$. High microvessel density, as measured by endoglin, has been related to a disseminated cancer and poor prognosis of breast, prostate, cervix, gastrointestinal and head and neck cancers (19-22). Besides this, endoglin has been shown to activate signaling pathways that prevent endothelial cell apoptosis (18).

Mechanisms of lymphangiogenesis are less known and fewer specific antibodies are available to study the characteristics of lymphatic vessels. Podoplanin is expressed in the endothelium of lymph vessels, and is used in lymph vessel staining. The monoclonal antibody D2-40 adheres to podoplanin and is used for the measurement of lymph vessel density. Its high expression has been related to cancer aggressiveness (23).

In this study, we compared the two staining methods, CD34 and endoglin, for their accuracy in assessing angiogenesis in ovarian cancer and evaluated the differences in microvessels according to the type of tumor. Additionally, the significance of lymph vessels was examined in relation to the prognosis of ovarian cancer patients.

\section{Patients and Methods}

Patient and data collection. This study included 139 women, who were diagnosed and operated for epithelial ovarian tumors at Kuopio University Hospital between 1999 and 2007. Of these women, 86 had malignant epithelial ovarian cancer, 17 had borderline and 36 had benign tumors (Tables I and II). The histological subtypes and the grades of tumors were evaluated according to the World Health Organization (WHO 2003) Classification of Tumors (24). Tumor tissue samples were collected during primary surgery and samples were analyzed using immunohistochemistry. The follow-up time ended in November 2019. Exclusion criteria included: nonepithelial neoplasms, the need for neoadjuvant therapy, and unresectable cancer. Staging followed the criteria of the International Federation of Gynecology and Obstetrics (FIGO 1988). Most included cancer patients were treated with platinum-based chemotherapy after operation. In total, $42 \%(n=36)$ received paclitaxel and carboplatin as their primary adjuvant treatment. 30\% $\quad(n=26)$ started chemotherapy with the combination of paclitaxel and carboplatin, but were changed to single carboplatin, because of side effects. Furthermore, $13 \%(n=11)$ had single carboplatin. Three women were treated with cisplatin combined with cyclophosphamide, two women with gemcitabine and carboplatin, and one with cisplatin and paclitaxel. For seven patients, either chemotherapy was not administered because of stage IA cancer or information on the treatment was not available. None of the patients received bevacizumab as part of their first line treatment (12). The study was approved by the Ethical Committee of the Kuopio University Hospital, Finland (26/99). Written informed consent was obtained from all patients participating the study. This study adhered to the principles of the Declaration of Helsinki.

Immunohistochemistry. Tissue samples were embedded in paraffin and cut into 5- $\mu \mathrm{m}$-thick sections. Next, the sections were processed for microvessel staining with anti-CD34 antibody (mouse monoclonal antibody CD34, Vectastain Elite kit, Dako, Glostrup, Denmark, 1:500) and anti-CD105 antibody (mouse monoclonal antibody CD105, Biocare Mach 1 kit, 1:90). Lymph vessel staining was performed using an anti-D2-40 antibody (mouse monoclonal antibody D2-40, Vectastain Elite kit, Dako, Glostrup, Denmark, 1:200). Immunostained samples were evaluated with use of the Olympus AX70 microscope (Olympus Optical, Tokyo, Japan). Three hot spots with the highest density of microvessels or lymph vessels per sample were chosen and photographed with $\times 200$ magnification (25-27). Necrotic areas were not counted. Images were analyzed with the analySIS-program (Olympus, Soft Imaging System, GmbH, Münster, North Rhine-Westphalia, Germany) that measures microvessel density (MVD, vessels $/ \mathrm{mm}^{2}$ ), lymphatic vessel density (LVD, vessels $/ \mathrm{mm}^{2}$ ), the mean size/ area of the vessels $\left(\mu \mathrm{m}^{2}\right)$, the percentage of vessels $(\%)$ in the tumor and the number of vessels $(\mathrm{N})$.

Immunostaining of VEGFs and VEGF receptors was processed and evaluated as in our previously published study (12).

Statistical analysis. Statistical analyses were performed using Statistical Package for Social Sciences (SPSS for Windows version 24, 1989-2016, SPSS Inc., Chicago, IL, USA). Kruskal-Wallis test was performed followed by the Mann-Whitney test for multiple comparisons of continuous variables. For analyses of the association of the clinicopathological factors and survival, each variable was dichotomized into low and high groups using the median values as a cut-off. The chi-squared test was performed to analyze frequency tables for categorial variables. The impact of the variables on the progression-free survival and overall survival was defined with the Kaplan-Meier method. The correlations were analyzed with the Spearman's test (12). 
Table I. Characteristics of 139 studied women with ovarian tumors

\begin{tabular}{lccc}
\hline & $\begin{array}{c}\text { Benign } \\
\text { tumors }\end{array}$ & $\begin{array}{c}\text { Borderline } \\
\text { tumors }\end{array}$ & $\begin{array}{c}\text { Malign } \\
\text { tumors }\end{array}$ \\
\hline $\begin{array}{l}\text { Total } \\
\text { Age by the time of }\end{array}$ & $\begin{array}{c}36(100) \\
\text { diagnosis, median (years) }\end{array}$ & $17(100)$ & $86(100)$ \\
$\begin{array}{l}\text { Histological subtype } \\
\text { Serous }\end{array}$ & $21(58)$ & $11(65)$ & $58(29-8)$ \\
Mucinous & $15(42)$ & $6(35)$ & $11(13)$ \\
Endometrioid cancer & & & $15(17)$ \\
Clear cell cancer & & & $5(6)$ \\
Other & & & $4(5)$ \\
\hline
\end{tabular}

Values are $\mathrm{N}(\%)$ or median (range).

\section{Results}

Association of microvessel staining with ovarian tumor type. There were significant differences in the association between microvessel parameters as assessed by CD34-staining and the type of ovarian tumor (Figure 1, Table III). In malignant tumors, the microvessel density, mean area, the percentage, and the number of microvessels assessed by CD34 were significantly higher compared to the respective values of the benign tumors $(p<0.001 ; p=0.044)$ (Figure 2A-D). In addition, in malignant tumors, microvessel density and the number of vessels were higher than those in borderline tumors $(p=0.010)$ (Figure 2B and $\mathrm{D}$ ). The mean area and the percentage of microvessels of borderline tumors were significantly larger than those in benign tumors $(p=0.001 ; p<0.001)$ (Figure $2 \mathrm{~A}$ and $\mathrm{C}$ ).

Endoglin staining showed, that the microvessel density in ovarian cancer was significantly higher $(31 \%)$ than that in borderline tumors $(p=0.046)$, and in benign tumors, the difference was even higher $(70 \%)(p<0.001)$ (Figure $2 \mathrm{~F})$. Additionally, there were $35 \%$ more vessels in malignancies compared to borderline tumors $(p=0.036)$ and double more compared to benign tumors as assessed by endoglin staining $(p<0.001)$ (Figure 2H) (Table III). Mean size and percentage of microvessels in tumors assayed by endoglin were not different between malignant, borderline and benign tumors (Figure 2E and G).

Lymph vessel features were not related to tumor type (Figure 2I-L); there were no significant differences in lymph vessel density, percentage, size or number of lymph vessels between different tumor histologies.

Relation of clinicopathological data to the microvessels in ovarian cancer. The higher percentage of microvessels observed by CD34 staining ( $p=0.001)$ and the greater number of vessels seen by endoglin $(p=0.012)$ staining in ovarian malignancies were associated significantly with a larger residual tumor $(>1 \mathrm{~cm})$ after primary surgery (Table IV).
Table II. Clinical characteristics of the 86 ovarian cancer patients.

\begin{tabular}{|c|c|}
\hline Characteristic & Ovarian carcinoma $\mathrm{N}(\%)$ \\
\hline \multicolumn{2}{|l|}{ Histologic subtype } \\
\hline Serous & $51(59)$ \\
\hline High grade & 45 \\
\hline Low grade & 6 \\
\hline Endometrioid & $15(17)$ \\
\hline High grade & 13 \\
\hline Low grade & 2 \\
\hline $\mathrm{Ca} 12-5, \mathrm{kU} / 1$ & $363(5-10100)$ \\
\hline \multicolumn{2}{|l|}{ FIGO stage } \\
\hline I & $12(13)$ \\
\hline II & $10(12)$ \\
\hline III & $46(53)$ \\
\hline IV & $18(22)$ \\
\hline \multicolumn{2}{|l|}{ Histological grade* } \\
\hline 1 & $9(12)$ \\
\hline 2 & $25(33)$ \\
\hline 3 & $41(55)$ \\
\hline Ascites & $60(70)$ \\
\hline No ascites & $16(19)$ \\
\hline Unknown & $10(11)$ \\
\hline \multicolumn{2}{|l|}{ Metastasis in lymph nodes } \\
\hline Yes & $5(6)$ \\
\hline No & $22(26)$ \\
\hline Unknown & $59(69)$ \\
\hline \multicolumn{2}{|l|}{ Residual tumor at primary surgery } \\
\hline None & $40(47)$ \\
\hline$\leq 1 \mathrm{~cm}$ & $8(9)$ \\
\hline$>1 \mathrm{~cm}$ & $38(44)$ \\
\hline \multicolumn{2}{|l|}{ Chemotherapy response } \\
\hline Complete response & $57(66)$ \\
\hline Partial response & $4(5)$ \\
\hline Stable disease & $2(2)$ \\
\hline Progressive disease & $5(6)$ \\
\hline No chemotherapy & $5(6)$ \\
\hline No data & $13(15)$ \\
\hline Tumor recurrence & $49(57)$ \\
\hline No recurrence & $26(30)$ \\
\hline No data on recurrence & $11(13)$ \\
\hline \multicolumn{2}{|l|}{ Patient status } \\
\hline Dead from ovarian cancer & $52(60)$ \\
\hline Dead for other/unknown reason & $6(7)$ \\
\hline Alive & $28(33)$ \\
\hline Median follow-up, months & $66(0-198)$ \\
\hline
\end{tabular}

Values are presented as $\mathrm{N}(\%)$ or as median (range). *Mucinous tumors were not graded.

The high percentage of lymph vessels in ovarian cancer predicted significantly greater probability of lymph node metastasis $(p=0.008)$. The higher lymph vessel density $(p=0.013)$ and number of lymph vessels in the tumor $(p=0.042)$ were significantly associated with ovarian cancer recurrence. In addition, features of active lymphangiogenesis including high density and number of lymphatics, were related to high-grade cancer $(p=0.002 ; p=0.035)$, and high 

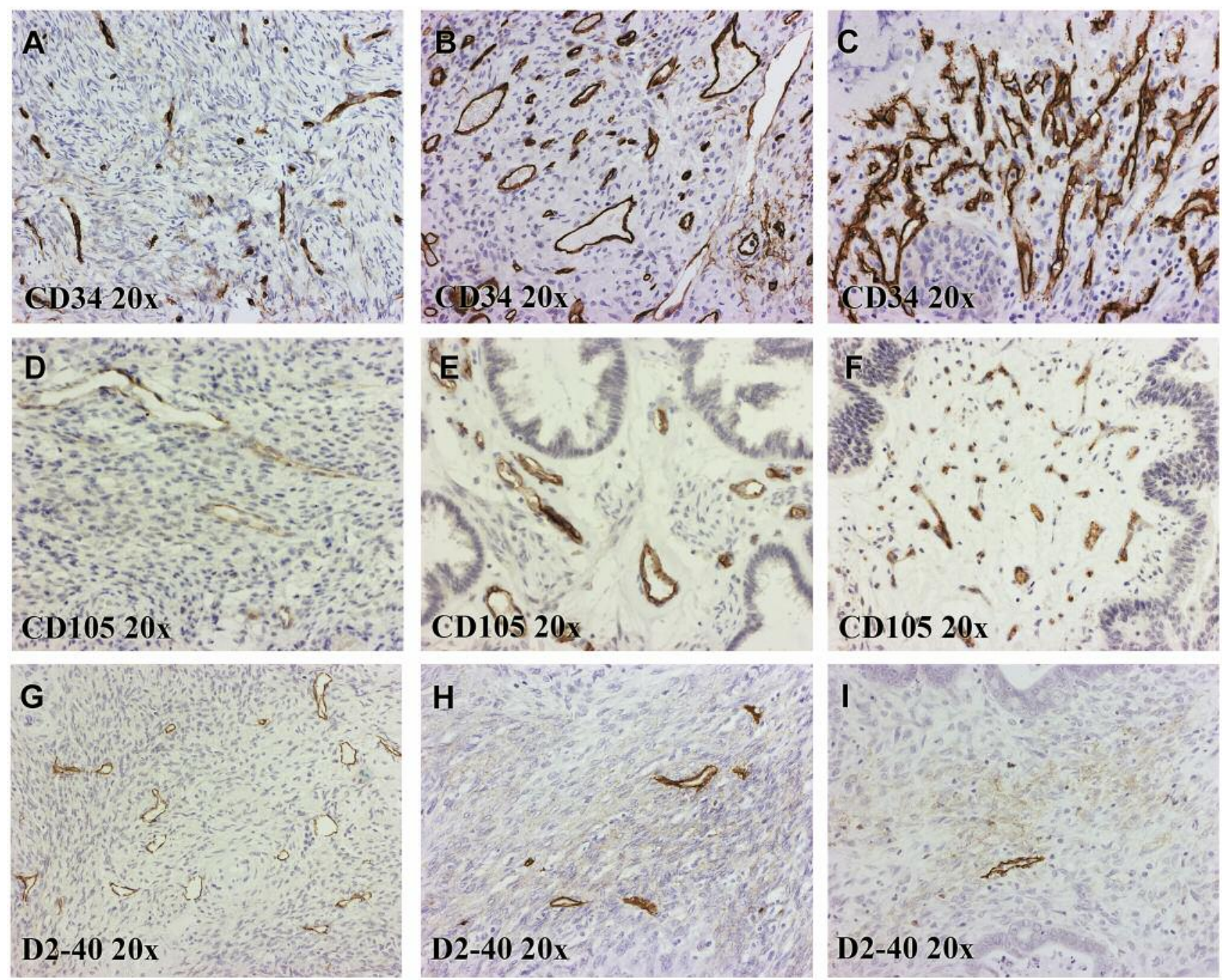

Figure 1. Immunohistochemistry of micro- and lymph vessels. By CD34 staining more microvessels were found in malignant tumors (C) compared to the borderline $(B)$ or benign tumors $(A)$. Also, by endoglin (CD105) staining, microvessels were more profuse in cancer $(F)$ than in borderline $(E)$ or benign tumors $(D)$. The percentage of lymph vessels in the tumor was higher in serous cancer $(G)$ compared to the malignant tumors of other histology (H, I; mucinous carcinoma, endometrioid cancer).

percentage of lymph vessels to serous histologic type $(p=0.010)$ (Table IV).

The results were comparable when analyzing categorial variables by Pearson's chi-squared test and as continuous variables by Kruskal-Wallis test.

Progression-free survival and overall survival of the ovarian cancer patients. The median follow-up time was 66 months (range=0-198 months). At the end of follow-up, 58 (67\%) of the ovarian cancer patients had died. Progression-free survival analysis included 75 patients, of whom $65 \%$ experienced recurrence. The median progression-free survival was $16 \pm 12$ months.
The small size of the lymph vessels predicted shorter overall survival of the ovarian cancer patients (medians: 42 $v s .77$ months; $p=0.035$ ) (Figure 3).

The higher number of microvessels assessed by CD34 staining was associated with longer progression-free survival $(p=0.020)$.

In endoglin staining, the properties of microvessels did not reach significance in association with cancer prognosis. However, the tendency was clear: the more vessels in the tumor, the shorter the overall survival was.

Correlation between density, percentage, size and number of microvessels, with VEGF and VEGF receptor expression in 


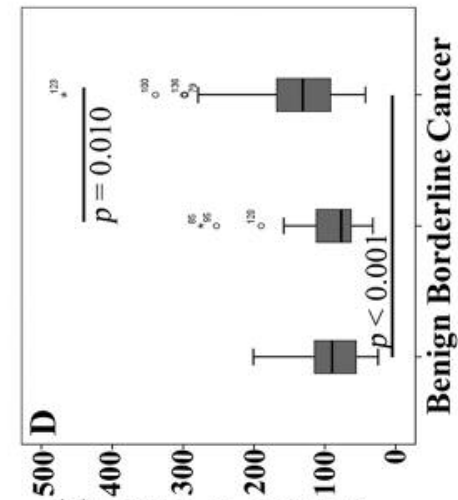

(u) sjəssəs jo dəquin $N$

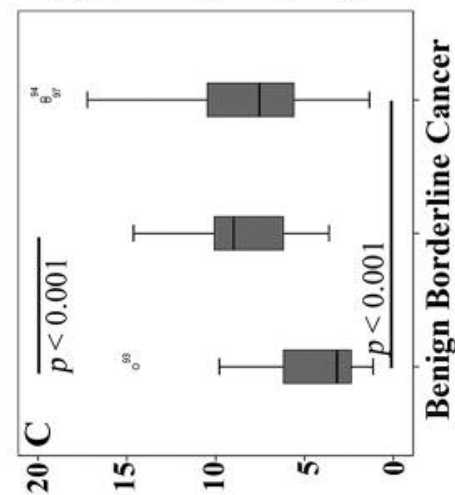

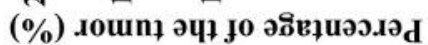
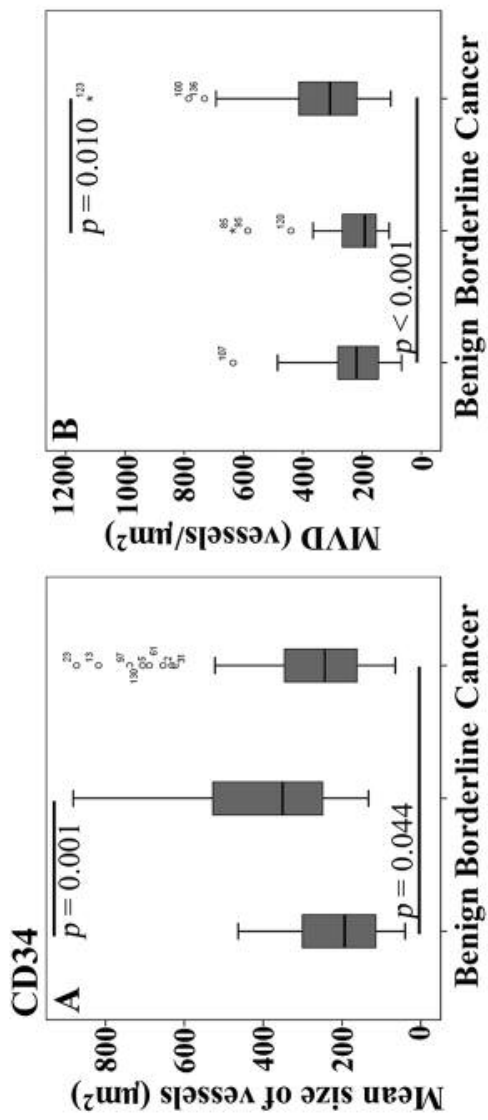

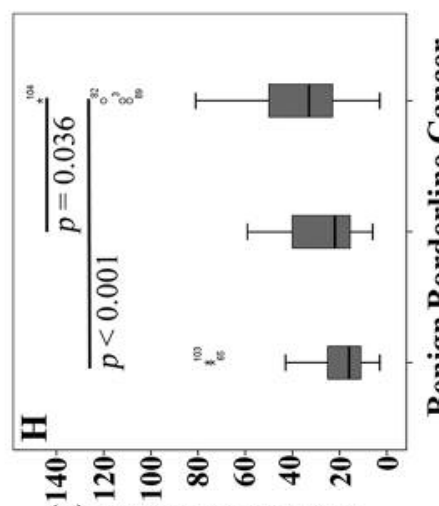

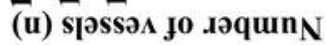

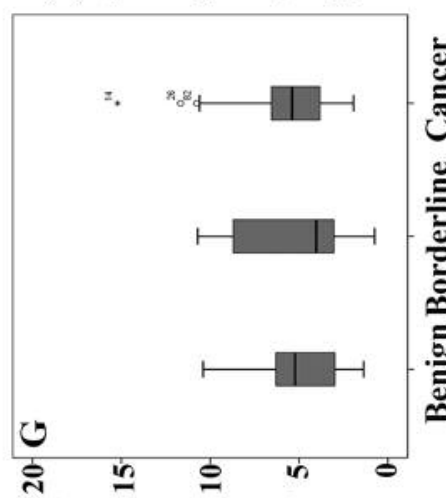

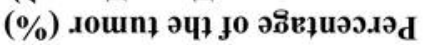
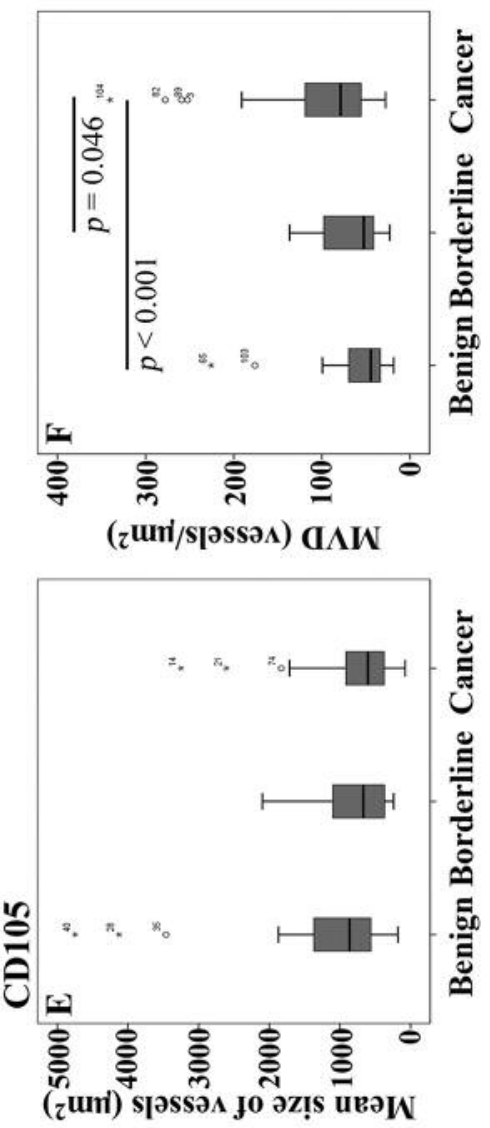

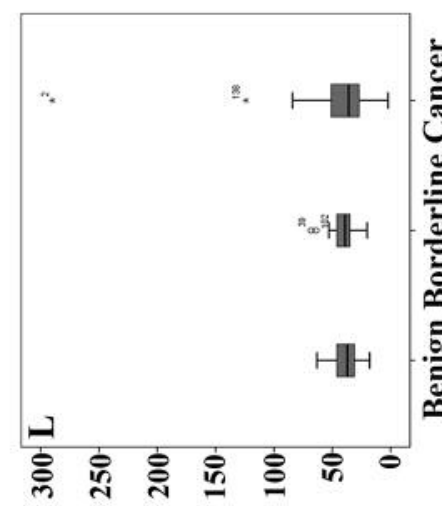

(u) s[əssəs jo .rəquin $\mathrm{N}$

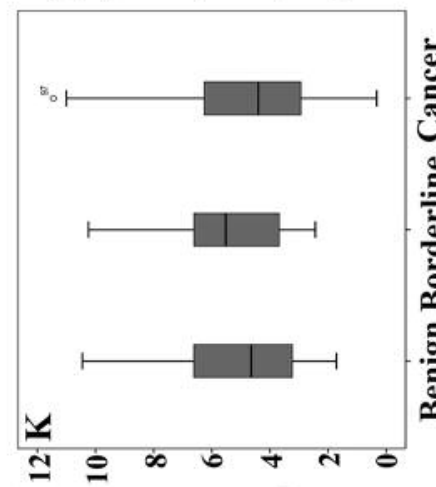

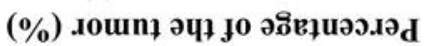
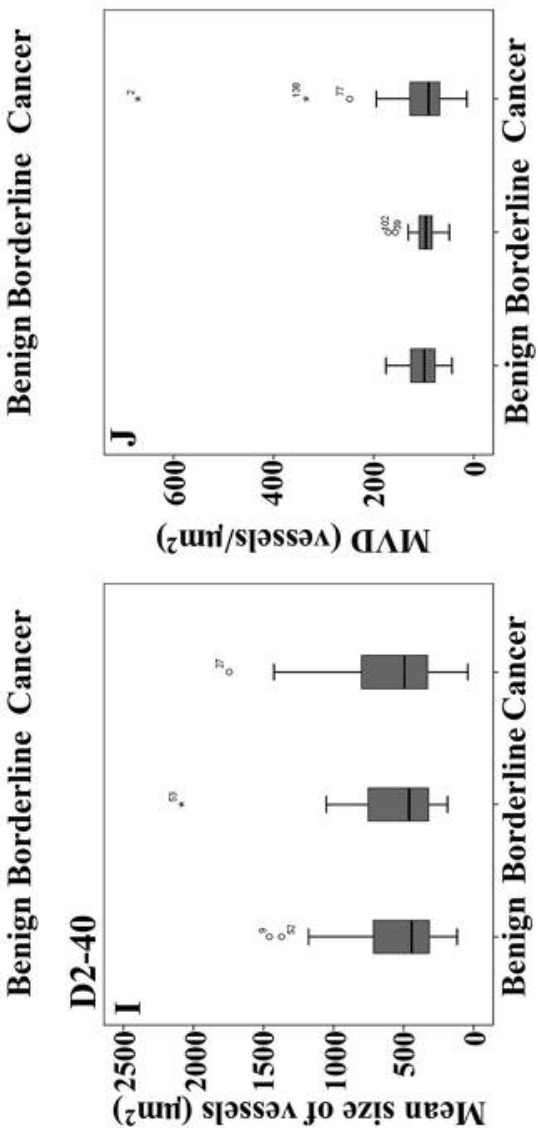

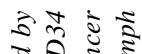

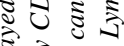

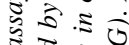

ठิ

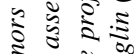

इ 5 :

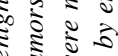

₹ $5 \frac{5}{2}$

2 ปิ

จ. इ

इ ฐ

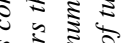

ई ईई ई

芯企焉

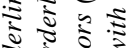

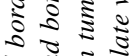

ㄹำ

ङ

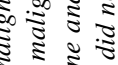

$3: \frac{2}{2}: 2$

요

20

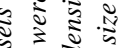

के 05

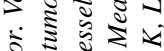

इ ปे

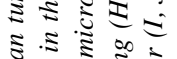

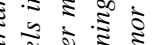

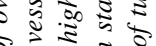

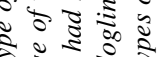

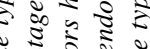

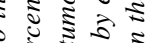

政

इ इ छ

跑

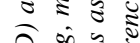

ปิ

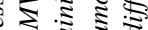

곡ำ

हิे

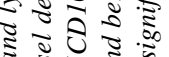

匀

วิ

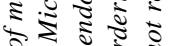

ये को

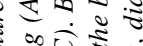

\&.

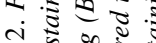

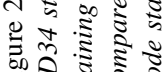


Table III. Features of microvessels in relation to the type of ovarian tumor.

\begin{tabular}{lcccc}
\hline & Benign tumors & Borderline tumors & Malignant tumors & $p$-Values \\
\hline CD34 & & & & \\
Microvessel density $\left(\right.$ vessels $\left./ \mathrm{mm}^{2}\right)$ & $232.55 \pm 20.35$ & $255.39 \pm 39.84$ & $340.69 \pm 18.58$ & $<0.001 ; 0.010$ \\
Percentage of microvessels in tumor $(\%)$ & $4.59 \pm 0.54$ & $8.57 \pm 0.77$ & $8.32 \pm 0.42$ & $<0.001 ;<0.001$ \\
Mean size of the vessels $\left(\mu \mathrm{m}^{2}\right)$ & $213.13 \pm 20.03$ & $414.25 \pm 54.75$ & $291.82 \pm 19.89$ & $0.001 ; 0.044$ \\
Number of microvessels $(\mathrm{N})$ & $92.54 \pm 7.70$ & $108.59 \pm 17.41$ & $142.99 \pm 7.91$ & $<0.001 ; 0.010$ \\
& & & & \\
Endoglin $(\mathrm{CD} 105)$ & $55.55 \pm 7.38$ & $71.81 \pm 9.42$ & $53.94 \pm 6.12$ & $<0.001 ; 0.046$ \\
Microvessel density $\left(\right.$ vessels $\left./ \mathrm{mm}^{2}\right)$ & $4.84 \pm 0.42$ & $5.06 \pm 0.82$ & $\mathrm{~ns}$ & $\mathrm{~ns}$ \\
Percentage of microvessels in tumor $(\%)$ & $1,212.25 \pm 204.51$ & $755.26 \pm 124.10$ & $741.65 \pm 57.53$ & $<.25$ \\
Mean size of the vessels $\left(\mu \mathrm{m}^{2}\right)$ & $19.48 \pm 2.6$ & $28.86 \pm 4.40$ & $38.93 \pm 2.64$ & $<0.001 ; 0.036$ \\
Number of vessels $(\mathrm{N})$ & & & & \\
\hline
\end{tabular}

MVD: Microvessel density; ns: non-significant. Values are mean \pm standard error (SE).

Table IV. Clinicopathological data of the microvessels in ovarian cancer.

\begin{tabular}{|c|c|c|c|c|c|c|}
\hline & Histology & Grade & Stage & $\begin{array}{l}\text { Recidual tumor } \\
\text { size }>1 \mathrm{~cm}\end{array}$ & $\begin{array}{l}\text { Lymph node } \\
\text { metastases }\end{array}$ & Recurrence \\
\hline \multicolumn{7}{|l|}{ CD34 } \\
\hline Percentage of microvessels in tumor (\%) & ns & ns & ns & 0.001 & ns & ns \\
\hline \multicolumn{7}{|l|}{ Endoglin (CD105) } \\
\hline Percentage of microvessels in tumor (\%) & ns & ns & 0.040 & ns & ns & ns \\
\hline Number of vessels (n) & ns & ns & ns & 0.012 & ns & ns \\
\hline \multicolumn{7}{|l|}{ D2-40 } \\
\hline Lymph vessel density (vessels/mm²) & ns & 0.002 & $\mathrm{~ns}$ & ns & $\mathrm{ns}$ & 0.013 \\
\hline Percentage of lymph vessels in tumor (\%) & 0.010 & ns & ns & ns & 0.008 & ns \\
\hline Number of lymph vessels (n) & ns & 0.035 & ns & ns & ns & 0.042 \\
\hline
\end{tabular}

LVD: Lymph vessel density; ns: non-significant. $p$-Values were determined by Kruskall-Wallis test.

ovarian tumors. There were weak but significant correlations between parameters of microvessels and the expression of VEGF-A and VEGFR3 in primary ovarian cancer. As assessed by CD34 staining, the mean size ( $\mathrm{r}=0.3, p=0.014)$ and number of vessels $(\mathrm{r}=0.2, p=0.049)$ correlated positively with the cytoplasmic expression of VEGF-A.

Endoglin staining showed a weak correlation between microvessel density $(\mathrm{r}=0.2 ; p=0.034)$ and the number of vessels $(\mathrm{r}=0.2, p=0.03)$ with VEGFR3 expression in epithelial cancer cells.

In borderline tumors, percentage and size of vessels, as analysed by endoglin, correlated strongly with the expression of VEGF and VEGF receptors. The mean size of vessels correlated significantly with the expression of VEGF-A $(\mathrm{r}=0.7 ; p=0.007)$, VEGFR1 $(\mathrm{r}=0.6 ; p=0.014)$ and VEGFR3 $(\mathrm{r}=0.6 ; p=0.018)$. In addition, VEGF-D showed strong correlation with the percentage of the microvessels in the tumor $(\mathrm{r}=0.6 ; p=0.038)$.

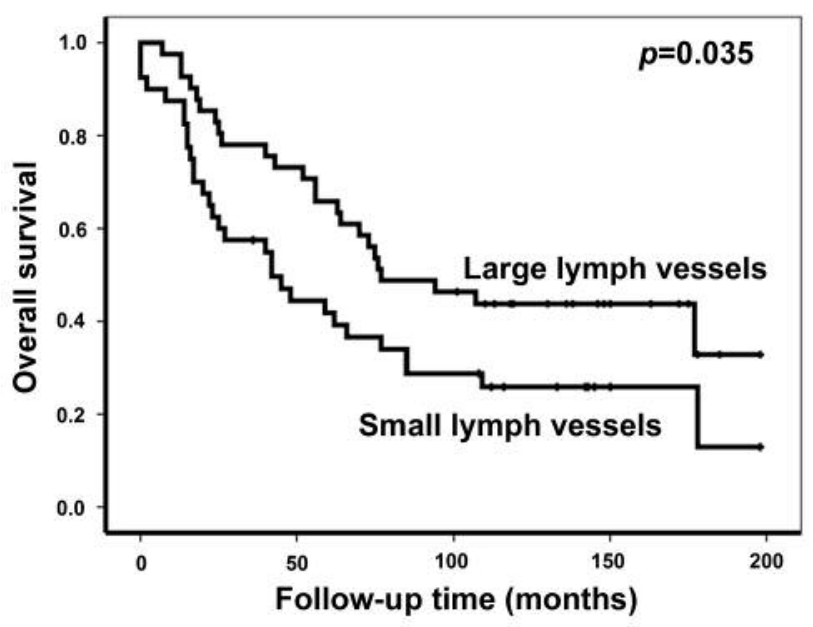

Figure 3. Kaplan-Meier curve of prognostic significance of lymph vessels. Small size of lymph vessels predicted poor overall survival in ovarian cancer. 
In benign tumors, the percentage of microvessels as analysed by CD34 staining, correlated moderately negatively with the expression of VEGF-C ( $\mathrm{r}=-0.4, p=0.042)$. Furthermore, VEGFR3 correlated strongly and negatively with the percentage of the vessels $(\mathrm{r}=-0.5, p=0.002)$ and weakly with the mean size of vessels $(\mathrm{r}=-0.3, p=0.046)$ assessed by CD34 staining and with the number of vessels $(\mathrm{r}=-0.4 ; p=0.046)$ assessed by endoglin staining. VEGFR2 did not correlate with the parameters of microvessels.

Correlation of density and number of microvessels between CD34 and endoglin staining. Microvessel density assessed by CD34 staining showed a weak but significant correlation with the microvessel density assessed by endoglin staining $(\mathrm{r}=0.2, p=0.044)$. Further, the number of microvessels correlated positively with CD34 and endoglin staining $(\mathrm{r}=0.2, p=0.022)$.

\section{Discussion}

According to this study, the microvessel density was higher in malignant tumors compared to borderline and benign tumors, as assayed by endoglin and CD34 antibodies. This implies that both mature and immature vessels define malignant tumors as reported in earlier studies $(13,28)$.

Angiogenesis has usually been measured by investigating the most highly vascularized areas of the samples, so called hot spots, and calculating the microvessel density $(13,29)$. The number of hot spots has varied from one to ten in earlier studies $(30,31)$. Here, three hot spots were chosen as in the studies of Raspollini (2005) and Rubatt (2015) (29, 32).

High microvessel density has been linked to shorter (13) as well as longer progression free survival (14). In our study the prognostic value of microvessel density differed according to the antibody used: higher number of vessels assessed by CD34 was associated with longer progression free survival but that assayed by endoglin showed an opposite trend. According to a recent meta-analysis on microvessel density, high value of microvessel density was associated with poor prognosis and the most relevant antibody was found to be that against CD34 (13). However, we could not confirm these results.

The controversial results could be explained by the properties of the antibodies, i.e. they stain vessels in different phase of maturity. It is possible that the profuse original vessels and the new formed vessels stained by the CD34 antibody contribute to the access of the chemotherapeutics to the tumor leading to the better response and longer progression free time (33). Besides, tumors could also obtain sufficient oxygen and nutrients along the old functioning vessels for their growth and dissemination (34).

By endoglin staining the density, percentage, size and number of microvessels did not reach statistical significance as a prognostic marker although a tendency of worse prognosis was related to the more profuse microvessels. The active neoangiogenesis of the tumor shown by endoglin staining could predict the ability of cancer cells to disseminate. On the other hand, the access of the chemotherapeutics to the tumor through immature vessels might not be as effective as through mature vessels. The different results with CD34 and endoglin staining demonstrate that they measure distinct types of vessels. Further the superiority of one or the other antibody in estimating the prognosis of ovarian cancer could not be claimed in this study contrary to earlier studies (30).

For the first time, we could demonstrate that lymphangiogenic markers in ovarian cancer were related to the more aggressive cancer and worse prognosis. The smaller size of the lymph vessels predicted significantly shorter overall survival of ovarian cancer patients. Further, higher lymph vessel density in malignant tumors predicted high grade cancer and high percentage of lymph vessels in the tumor was associated with lymph node metastases. In different types of cancer, high lymph vessel density has been linked to the lymph node metastases and small intratumoral lymph vessels have also been associated with worse prognosis (23, 34-36). However, lymph vessel parameters didn't differ between benign, borderline and malignant tumors in our study.

Interestingly, this study shows that at least at protein level, evaluated by immunohistochemistry, vessel parameters were associated differently with VEGF and VEGF receptors depending on the malignancy level of the ovarian tumor. In malignant tumors, the correlation of vessel density and number to VEGF and its receptors was weak but positive, while in borderline tumors the correlation was strong. In contrast, in benign tumors the correlation of vessels to the VEGF or their receptors was the opposite, i.e. less vessels were associated with more receptors or VEGF. This may imply differences in the regulation of angiogenesis according to the tumor type or loss of the regulatory control.

The limitations of this study include the subjective assessment of the samples, primarily in choosing the hot spots, although all samples were examined the same way. However, an image analyzing program was used and the method is widely accepted and used in various studies offering semiquantitative analysis. Another weakness of the study was its retrospective nature, and collection time of the samples, when there was not yet antiangiogenic treatment available for the patients (37).

According to these results, the features of the microvessels could be used in evaluating the prognosis and aggressiveness of epithelial ovarian cancer. Lymph vessel density, percentage and size may predict the dissemination and prognosis of ovarian cancer. By both CD34 and endoglin staining the angiogenesis was found to be more active in malignant tumors 
compared to the benign ones. However, further studies are needed to examine the significance of lymph vessels in ovarian cancer patients and the great challenge would be to measure the effects of antiangiogenic therapy on the parameters of the microvessels in ovarian cancer.

\section{Conflicts of Interest}

The Authors disclose no conflicts of interest in relation to this study.

\section{Authors' Contributions}

MS wrote the manuscript, and analyzed statistics. HS and MA designed the study, collected the samples and clinical data, reviewed the data, and revised the manuscript. OTM analyzed the samples and statistics. SYH and VMK provided the conditions, materials, and laboratory services for the study. LKN revised the manuscript. All Authors have read and approved the manuscript.

\section{Acknowledgements}

The Authors would like to thank Mrs Helena Kemiläinen for her skillful technical assistance. This study was supported by The Cancer Foundation of Northern Savo, The Finnish Cultural Foundation, Kuopio University Hospital Research Foundation and VTR grant.

\section{References}

1 Bray F, Ferlay J, Soerjomataram I, Siegel RL, Torre LA and Jemal A: Global cancer statistics 2018: GLOBOCAN estimates of incidence and mortality worldwide for 36 cancers in 185 countries. CA Cancer J Clin 68: 394-424, 2018. PMID: 30207593. DOI: $10.3322 /$ caac. 21492

2 Cannistra SA: Cancer of the ovary. N Engl J Med 351: 25192529, 2004. PMID: 15590954. DOI: 10.1056/NEJMra041842

3 Burger RA, Brady MF, Bookman MA, Fleming GF, Monk BJ, Huang H, Mannel RS, Homesley HD, Fowler J, Greer BE, Boente $\mathrm{M}$, Birrer $\mathrm{MJ}$ and Liang SX: Incorporation of bevacizumab in the primary treatment of ovarian cancer. The $\mathrm{N}$ Engl J Med 365: 2473-2483, 2011. PMID: 22204724. DOI: 10.1056/NEJMoa 1104390

4 Perren TJ, Swart AM, Pfisterer J, Ledermann JA, PujadeLauraine E, Kristensen G, Carey MS, Beale P, Cervantes A, Kurzeder C, du Bois A, Sehouli J,Kimmig R, Stähle A, Collinson F, Essapen S, Gourley C, Lortholary A, Selle F, Mirza MR, Leminen A, Plante M, Stark D, Qian W, Parmar MKB and Oza AM: A phase 3 trial of bevacizumab in ovarian cancer. $\mathrm{N}$ Engl J Med 365: 2484-2496, 2011. PMID: 22204725. DOI: 10.1056/NEJMoa1103799

5 Mirza MR, Lundqvist ÅE, Birrer MJ, dePont Christensen R, Nyvang G, Malander S, Anttila M, Werner TL, Lund B, Lindahl G, Hietanen S, Peen U, Dimoula M, Roed H, Ør Knudsen A, Staff S, Krog Vistisen A, Bjørge L and Mäenpää JU: Niraparib plus bevacizumab versus niraparib alone for platinum-sensitive recurrent ovarian cancer (NSGO-AVANOVA2/ENGOT-ov24): a randomised, phase 2, superiority trial. Lancet Oncol 20: 1409-1419, 2019. PMID: 31474354. DOI: 10.1016/S1470-2045(19)30515-7
6 Moore KN and Pignata S: Trials in progress: IMagyn050/GOG 3015/ENGOT-OV39. A Phase III, multicenter, randomized study of atezolizumab versus placebo administered in combination with paclitaxel, carboplatin, and bevacizumab to patients with newly-diagnosed stage III or stage IV ovarian, fallopian tube, or primary peritoneal cancer. Int J Gynecol Cancer 29: 430-433, 2019. PMID: 30630885. DOI: 10.1136/ijgc-2018-000071

7 Pasqualini R, Arap W and McDonald DM: Probing the structural and molecular diversity of tumor vasculature. Trends Mol Med 8: 563-571, 2002. PMID: 12470989. DOI: 10.1016/s14714914(02)02429-2

8 Morikawa S, Baluk P, Kaidoh T, Haskell A, Jain RK and McDonald DM: Abnormalities in pericytes on blood vessels and endothelial sprouts in tumors. Am J Pathol 160: 985-1000, 2002. PMID: 11891196. DOI: 10.1016/S0002-9440(10)64920-6

9 Baluk P, Morikawa S, Haskell A, Mancuso M and McDonald DM: Abnormalities of basement membrane on blood vessels and endothelial sprouts in tumors. Am J Pathol 163: 1801-1815, 2003. PMID: 14578181. DOI: 10.1016/S0002-9440(10)63540-7

10 Shibuya M: Vascular endothelial growth factor and its receptor system: physiological functions in angiogenesis and pathological roles in various diseases. J Biochem 153: 13-19, 2013. PMID: 23172303. DOI: $10.1093 / \mathrm{jb} / \mathrm{mvs} 136$

11 Wang J, Taylor A, Showeil R, Trivedi P, Horimoto Y, Bagwan I, Ewington L, Lam EW and El-Bahrawy MA: Expression profiling and significance of VEGF-A, VEGFR2, VEGFR3 and related proteins in endometrial carcinoma. Cytokine 68: 94-100, 2014. PMID: 24845798. DOI: 10.1016/j.cyto.2014.04.005

12 Sopo M, Anttila M, Hämäläinen K, Kivelä A, Ylä-Herttuala $S$, Kosma V, Keski-Nisula L and Sallinen H: Expression profiles of VEGF-A, VEGF-D and VEGFR1 are higher in distant metastases than in matched primary high grade epithelial ovarian cancer. BMC Cancer 19: 584, 2019. PMID: 31200683. DOI: 10.1186/s12885-019-5757-3

13 He L, Wang Q and Zhao X: Microvessel density as a prognostic factor in ovarian cancer: a systematic review and meta-analysis. Asian Pac J Cancer Prev 16: 869-874, 2015. PMID: 25735275. DOI: 10.7314/APJCP.2015.16.3.869

14 Ogawa S, Kaku T, Kobayashi H, Hirakawa T, Ohishi Y, Kinukawa $\mathrm{N}$ and Nakano $\mathrm{H}$ : Prognostic significance of microvessel density, vascular cuffing and vascular endothelial growth factor expression in ovarian carcinoma: a special review for clear cell adenocarcinoma. Cancer Lett 176: 111-118, 2002. PMID: 11790460. DOI: 10.1016/S0304-3835(01)00754-6

15 Ruscito I, Cacsire Castillo-Tong D, Vergote I, Ignat I, Stanske M, Vanderstichele A, Glajzer J, Kulbe H, Trillsch F, Mustea A, Kreuzinger C, Benedetti Panici P, Gourley C, Gabra H, Nuti M, Taube ET, Kessler M, Sehouli J, Darb-Esfahani S and Braicu EI: Characterisation of tumour microvessel density during progression of high-grade serous ovarian cancer: clinicopathological impact (an OCTIPS Consortium study). Br J Cancer 119: 330-338, 2018. PMID: 29955134. DOI: 10.1038/s41416$018-0157-z$

16 Shen GH, Ghazizadeh M, Kawanami O, Shimizu H, Jin E, Araki $\mathrm{T}$ and Sugisaki Y: Prognostic significance of vascular endothelial growth factor expression in human ovarian carcinoma. Br J Cancer 83: 196-203, 2000. PMID: 10901370. DOI: 10.1054/bjoc.2000.1228

17 Paschoal JP and Bernardo V, Canedo NH, Ribeiro OD, CaroliBottino A and Pannain VL: Microvascular density of regenerative 
nodule to small hepatocellular carcinoma. BMC Cancer 14: 72, 2014. PMID: 24507660. DOI: 10.1186/1471-2407-14-72

18 Dallas NA, Samuel S, Xia L, Fan F, Gray MJ, Lim SJ and Ellis LM: Endoglin (CD105): A marker of tumor vasculature and potential target for therapy. Clin Cancer Res 14: 1931-1937, 2008. PMID: 18381930. DOI: 10.1158/1078-0432.CCR-07-4478

19 Martinez LM, Labovsky V, Calcagno MdL, Davies KM, Garcia Rivello H, Rivello HG, Bianchi MS, Wernicke A, Vallone VBF, Fernández Vallone VB and Chasseing NA: CD105 expression on CD34-negative spindle-shaped stromal cells of primary tumor is an unfavorable prognostic marker in early breast cancer patients PloS one 10: e0121421, 2015. PMID: 25803686. DOI: 10.1371/journal.pone. 0121421

20 Miyata Y, Mitsunari K, Asai A, Takehara K, Mochizuki Y and Sakai H: Pathological significance and prognostic role of microvessel density, evaluated using CD31, CD34, and CD105 in prostate cancer patients after radical prostatectomy with neoadjuvant therapy. Prostate 75: 84-91, 2015. PMID: 25307287. DOI: $10.1002 /$ pros.22894

21 Zijlmans HJ, Fleuren GJ, Hazelbag S, Sier CF, ef EJ, Kenter GG and Gorter A: Expression of endoglin (CD105) in cervical cancer. Br J Cancer 100: 1617-1626, 2009. PMID: 19352388. DOI: $10.1038 /$ sj.bjc.6605009

22 Mohamed S, Mohammed H, Ibrahim H, Mohamed E and Salah M: Role of VEGF, CD105, and CD31 in the prognosis of colorectal cancer cases. J Gastrointest Cancer 50: 23-34, 2019. PMID: 29110224. DOI: 10.1007/s12029-017-0014-y

23 Raica M, Cimpean AM and Ribatti D: The role of podoplanin in tumor progression and metastasis. Anticancer Res 28: 2997, 2008. PMID: 19031946.

24 Hanby AM and Walker C: Tavassoli FA and Devilee P: Pathology and Genetics: Tumours of the Breast and Female Genital Organs. WHO Classification of Tumours series - volume IV. Lyon, France: IARC Press. Breast Cancer Res 6, 2004. DOI: $10.1186 /$ bcr788

25 Salvesen HB, Gulluoglu MG, Stefansson I and Akslen LA: Significance of CD 105 expression for tumour angiogenesis and prognosis in endometrial carcinomas. APMIS 111: 1011-1018, 2003. PMID: 14629267. DOI: 10.1111/j.1600-0463.2003.apm 1111103.x

26 Solomon LA, Munkarah AR, Schimp VL, Arabi MH, Morris RT, Nassar H and Ali-Fehmi R: Maspin expression and localization impact on angiogenesis and prognosis in ovarian cancer. Gynecol Oncol 101: 385-389, 2006. PMID: 16443262. DOI: 10.1016/j.ygyno.2005.11.049

27 Yang S, Cheng H, Cai J, Cai L, Zhang J and Wang Z: PlGF expression in pre-invasive and invasive lesions of uterine cervix is associated with angiogenesis and lymphangiogenesis. APMIS 117: 831-838, 2009. PMID: 19845534. DOI: 10.1111/j.16000463.2009.02538.x

28 Jacquemier JD, Penault-Llorca FM, Bertucci F, Sun ZZ, Houvenaeghel GF, Geneix JA, Puig BD, Bardou VJ, Hassoun JA, Birnbaum D and Viens PJ: Angiogenesis as a prognostic marker in breast carcinoma with conventional adjuvant chemotherapy: a multiparametric and immunohistochemical analysis. J Pathol 184(2): 130-135, 1998. PMID: 9602702. DOI: 10.1002/(SICI) 1096-9896(199802)184:2<130::AIDPATH19>3.0.CO;2-W
29 Rubatt JM, Darcy KM, Hutson A, Bean SM, Havrilesky LJ, Grace LA, Berchuck A and Secord AA: Independent prognostic relevance of microvessel density in advanced epithelial ovarian cancer and associations between CD31, CD105, p53 status, and angiogenic marker expression: A Gynecologic Oncology Group study. Gynecol Oncol 112: 469-474, 2008. PMID: 19135712. DOI: $10.1016 /$ j.ygyno.2008.11.030

30 Taskiran C, Erdem O, Onan A, Arisoy O, Acar A, Vural C, Erdem M, Ataoglu $\mathrm{O}$ and Guner $\mathrm{H}$ : The prognostic value of endoglin (CD105) expression in ovarian carcinoma. Int $\mathrm{J}$ Gynecol Cancer 16: 1789-1793, 2006. PMID: 17009973. DOI: 10.1111/j.1525-1438.2006.00658.x

31 Raspollini MR, Amunni G, Villanucci A, Baroni G, Boddi V, Degl'innocenti DR and Taddei GL: Microvessel density in ovarian carcinoma: computer image analysis in patients with shorter and longer survival. Int J Gynecol Cancer 15: 844-849, 2005. PMID: 16174234. DOI: 10.1136/ijgc-00009577-200509 000-00021

32 Merritt WM and Sood AK: Markers of Angiogenesis in Ovarian Cancer. Dis Markers 23: 419-431, 2007. PMID: 18057525. DOI: $10.1155 / 2007 / 257602$

33 Chan JK, Loizzi V, Magistris A, Lin F, Rutgers J, Osann K, DiSaia PJ and Berman ML: Differences in prognostic molecular markers between women over and under 45 years of age with advanced ovarian cancer. Clin Cancer Res 10: 8538-8543, 2004.PMID: 15623636. DOI: 10.1158/1078-0432.CCR-04-0626

34 Mohammed R, Ellis I, Elsheikh S, Paish E and Martin S: Lymphatic and angiogenic characteristics in breast cancer: morphometric analysis and prognostic implications. Breast Cancer Res Treat 113: 261-273, 2009. PMID: 18293084. DOI: 10.1007/s 10549-008-9936-1

35 Nakamura Y, Yasuoka H, Tsujimoto M, Kurozumi K, Nakahara M, Nakao K and Kakudo K: Importance of lymph vessels in gastric cancer: a prognostic indicator in general and a predictor for lymph node metastasis in early stage cancer. J Clin Pathol 59: 77-82, 2006. PMID: 16394285. DOI: 10.1136/jcp. 2005.028779

36 Zhang S, Yu H and Zhang L: Clinical implications of increased lymph vessel density in the lymphatic metastasis of early-stage invasive cervical carcinoma: a clinical immunohistochemical method study. BMC Cancer 9: 64, 2009. PMID: 19232130. DOI: 10.1186/1471-2407-9-64

37 Ruscito I, Cacsire Castillo-Tong D, Vergote I, Ignat I, Stanske M, Vanderstichele A, Glajzer J, Kulbe H, Trillsch F, Mustea A, Kreuzinger C, Benedetti Panici P, Gourley C, Gabra H, Nuti M, Taube ET, Kessler M, Sehouli J, Darb-Esfahani S and Braicu EI: Characterisation of tumour microvessel density during progression of high-grade serous ovarian cancer: clinicopathological impact (an OCTIPS Consortium study). Br J Cancer 119(3): 330-338, 2018. PMID: 29955134. DOI: 10.1038/s41416018-0157-z
Received October 7, 2020

Revised October 23, 2020

Accepted October 28, 2020 